\title{
La formación de biopelículas y la calidad del agua en la consulta odontológica
}

\author{
Biofilm formation and water quality in the dental practice
}

Título abreviado: Biopelícula y calidad de agua en odontología

Silvia Campuzano¹, Laura Jiménez², Diana M Hernández ${ }^{3}$

\section{Resumen}

Objetivo. Recuperar y analizar la presencia de bacterias formadoras de biopelículas en las mangueras de la jeringa triple y de la pieza de mano que distribuyen el agua a las unidades dentales de la Fundación Universitaria San Martin. Método. Se realizó un estudio descriptivo de corte transversal con muestreo probabilístico. Se estudiaron las bacterias presentes en el agua recolectada en la jeringa triple y la pieza de mano, las cuales fueron seleccionadas al ser los instrumentos por los cuales transita el agua que entrará en contacto con el paciente. Se tomaron muestras antes y después de la consulta, de la jeringa triple con solo agua, con agua-aire y la pieza de mano. Se realizaron cultivos por filtración por membrana en medios Endo, Cetrimide y Sangre Azida. Resultados. Se encontraron $84 \%$ de muestras positivas para cocos Gram positivos, mientras que el $8 \%$ de las muestras presentaban aislamientos de bacilos Gram negativos, representado en E coli y P aeruginosa. La flora Gram positiva estuvo representada por Staphylococcus hominis y Staphylococcus epidermidis.

Palabras claves: bacterias, biofilm, flora Gram positiva, flora Gram negativa.

\section{Abstract}

Objetive. To recover and to analyze the presence of biofilm forming bacteria in the triple syringe and handpiece hoses, which distribute the water to the dental units from La Fundación Universitaria San Martin. Methods. A cross-sectional descriptive study was carried out with probabilistic sampling. We studied the bacteria present in the water collected in the triple syringe and the handpiece were selected because they are the instruments through which the water that will come into contact with the patient. Samples were taken before and after the consultation, of the triple syringe with only water, with air water and the handpiece. Cultures were performed by membrane filtration in Endo, Cetrimide and Blood Azida media. Results. We found $84 \%$ positive samples for Gram positive cocci, while there were $8 \%$ of samples, with isolates of Gram negative bacilli, represented in $\mathrm{E}$ coli and $\mathrm{P}$ aeruginosa. The Gram positive flora was represented by Staphylococcus hominis and Staphylococcus epidermidis

Keywords: Bacterias, Biofilm, flora Gram positive, flora Gram negative.

1. Docente investigadora del Grupo de Investigación IMPACTO. Universidad Colegio Mayor de Cundinamarca. Bogotá, Colombia.

2. Estudiantes Programa de Bacteriología y Laboratorio Clínico. Universidad Colegio Mayor de Cundinamarca.

3. Estudiantes Programa de Bacteriología y Laboratorio Clínico. Universidad Colegio Mayor de Cundinamarca.

Correspondencia: scampuzano@unicolmayor.edu.co 


\section{Introducción}

El agua es un recurso natural indispensable del cual hacen uso constante los odontólogos en su práctica profesional diaria, con este recurso realizan tratamientos dentales y algunos tipos de cirugías maxilofaciales; sirviendo ésta como medio para el lavado bucal del paciente, para el lavado de manos del odontólogo ó para la preparación de instrumentos y materiales requeridos previamente al tratamiento.

El agua utilizada en la mayoría de las clínicas dentales es recopilada en grandes tanques de almacenamiento y circula mediante redes de distribución "tuberías" conectadas a cada unidad dental, las cuales cuentan con un sistema de distribución de agua constituido por mangueras de plástico flexibles que están directamente conectadas a las piezas dentales (jeringa triple y pieza de manos).

Por esta razón, es primordial designar un propicio proceso de lavado, desinfección y mantenimiento de las tuberías y de los instrumentos dentales que están en contacto directo con el agua; con el fin de evitar así la colonización de bacterias adheridas entre sí las cuales forman las denominadas biopelículas, reconocidas como altamente infecciosas. Éstas pueden llegar a separarse y desprenderse para buscar un nuevo lugar al cual incrustarse, sirviendo como nicho para otros microorganismos patógenos y pueden así afectar la inocuidad del agua. Cuando este recurso es utilizado en procedimientos odontológicos, sirve como transporte de este tipo de bacterias hacia la cavidad bucal del paciente, y si se presenta laceración en los tejidos, pueden viajar por el torrente sanguíneo hasta llegar a comprometer crónicamente la salud de la persona y, en casos agudos, llegar hasta una septicemia.

Por tal motivo, es muy importante contar con una adecuada calidad bacteriológica del agua en las unidades dentales. Esto con el fin de brindar un ambiente clínico seguro, que reduzca, o en el mejor de los casos, elimine por completo el riesgo de adquirir enfermedades e infecciones cruzadas entre el paciente y el agua utilizada en el momento en que se realizan los procedimientos dentales. La calidad bacteriológica del agua potable en Colombia se mide de acuerdo al hallazgo de microorganismos indicadores de contaminación como los Coliformes totales y Coliformes fecales. De acuerdo a la Resolución 2115 del 2007 se exige la ausencia de estas bacterias en el agua $(0 \mathrm{UFC} / 100 \mathrm{ml})$ y la ausencia de microorganismos altamente patógenos.

Estos parámetros son requerimientos mínimos que debe tener el agua manipulada en las clínicas odontológicas; ya que ésta tiene contacto directo con las piezas dentales, con la mucosa bucal de los diferentes pacientes. Tiene especial interés la población de niños, ancianos y personas inmuno comprometidas, quienes poseen una mayor predisposición de adquirir cualquier tipo de infección.

\section{Biopelículas}

Las biopelículas son comunidades microbianas que se adhieren a las superficies sólidas donde hay suficiente humedad (incluidos los tejidos de plantas y animales). Los factores que influyen para su crecimiento son la luz, la temperatura, los nutrientes, la respiración (oxígeno) y el flujo de agua.

Se pueden formar en superficies bióticas y abióticas, debido a su respuesta a condiciones adversas del medio ambiente (1). Los microorganismos se unen a un entorno acuoso donde secretan una matriz protectora voluminosa y viscosa compuesta principalmente de polisacáridos complejos de forma tridimensional que adicionalmente puede incorporar sustancias inorgánicas de su entorno, albergando múltiples tipos de microorganismos como bacterias, hongos, protozoos, amebas y algas (2).

\section{Proceso de formación y ciclo de las biopelículas en las mangueras de una unidad dental}


La formación de biopelículas, la cual supera 105 y 107 células/cm 2 en entornos acuosos, en una unidad dental (tuberías, tanques, lava manos y fregaderos), a menudo comienza con la formación de una película de aire de compuestos inorgánicos desde el medio ambiente, y se van adhiriendo microorganismos debido a las condiciones de estos lugares (las bacterias Gram negativas aerobias heterótrofas, son capaces de colonizar más rápido las tuberías plásticas que se manejan frecuentemente en las unidades dentales). Al estar adjuntos a la superficie se les facilita absorber nutrientes y se vuelven resistentes ante la escases del alimento $(3,4)$.

Uno de los requisitos que reúnen las unidades es el flujo de agua lento, accediendo a un pequeño estancamiento y proporcionando la acumulación pronta de bacterias ambientales, entre estas las patógenas, que se encuentran en los ductos de salida de agua, y son: Legionella spp., Pseudomonas spp., Staphylococcus spp. y Mycobacterium spp. (No tuberculosis). Sin embargo, la mayoría de estos organismos tienen un potencial patogénico mínimo en huéspedes inmunocompetentes $(6,7)$.

Pseudomonas aeruginosa, un bacilo Gram negativo, a pesar de ser una bacteria que no puede unirse a una superficie en caso de existir calcio y sodio; al salir de los ductos de agua, por ejemplo las piezas de mano y jeringas triples generan aerosoles y gotas de agua, que se ha demostrado, causa infección oral en pacientes $(6,7)$.

Los colonizadores iniciales se encargan entonces de ejecutar la primera fase del ciclo; la adhesión, que puede ser activa o pasiva (1), se fijan al área a través de fuerzas débiles y reversibles de Van Der Waals y posteriormente se unen de manera más permanente por otros métodos.

Una adhesión pasiva o por quimiotáxis es en el caso de las bacterias que poseen alguna sustancia de unión, como fimbrias (en el caso de las bacterias móviles), proteínas de adhesión (en el caso de algunas Gram positivas inmóviles), por las albúminas, lisozimas, glicoproteínas y lípidos que son algunos de los productos que ayudan a la unión directamente con la superficie.

La unión activa es cuando las bacterias requieren de una exposición prolongada al medio ambiente para la colonización $(1,4)$. Esta capa proporciona sitios de conexiones iníciales más diversos para otros microorganismos, entonces comienza la fase del crecimiento; la cual se considera la segunda fase del ciclo. Se da cuando las bacterias se dividen y las células hijas se extienden a lo largo formando microcolonias, éstas pierden sus apéndices de motilidad (flagelos y otros) y van produciendo un complejo extracelular de polisacáridos adherentes. Después de varias capas, en los primeros microorganismos se va implantando un metabolismo anaerobio causando lentitud en su velocidad de multiplicación y comienza así la formación del glicocalix o matriz formada de polisacáridos $(3,4)$. Allí también se encuentran inclusiones físicas de hongos, parásitos que pueden flotar lentamente en el agua $(1,5)$.

En la tercera y última etapa, la matriz adquiere grosor y complejidad mostrando ser una organización tridimensional, comportándose como una barrera amortiguadora de cambios bruscos del ambiente exterior; con ello también se forman canales de aguas que separan las aerobias de las anaerobias y permiten el transporte de materias que se realiza de afuera hacia adentro. Es decir, desde las que están expuestas al flujo de agua hacia las que se encuentran adheridas y cohesionadas a la superficie del medio de distribución de agua o bacterias sésiles, aquí el $\mathrm{pH}$ se convierte en un factor que diferencia lo interno de lo externo, adentro el $\mathrm{pH}$ se vuelve más ácido que la capa cerca al flujo del agua $(3,4)$.

La figura 1, muestra la distribución de una biopelícula por capas que simulan las colonias bacterianas. 
Figura 1. Estructura básica del biofilm en una tubería.

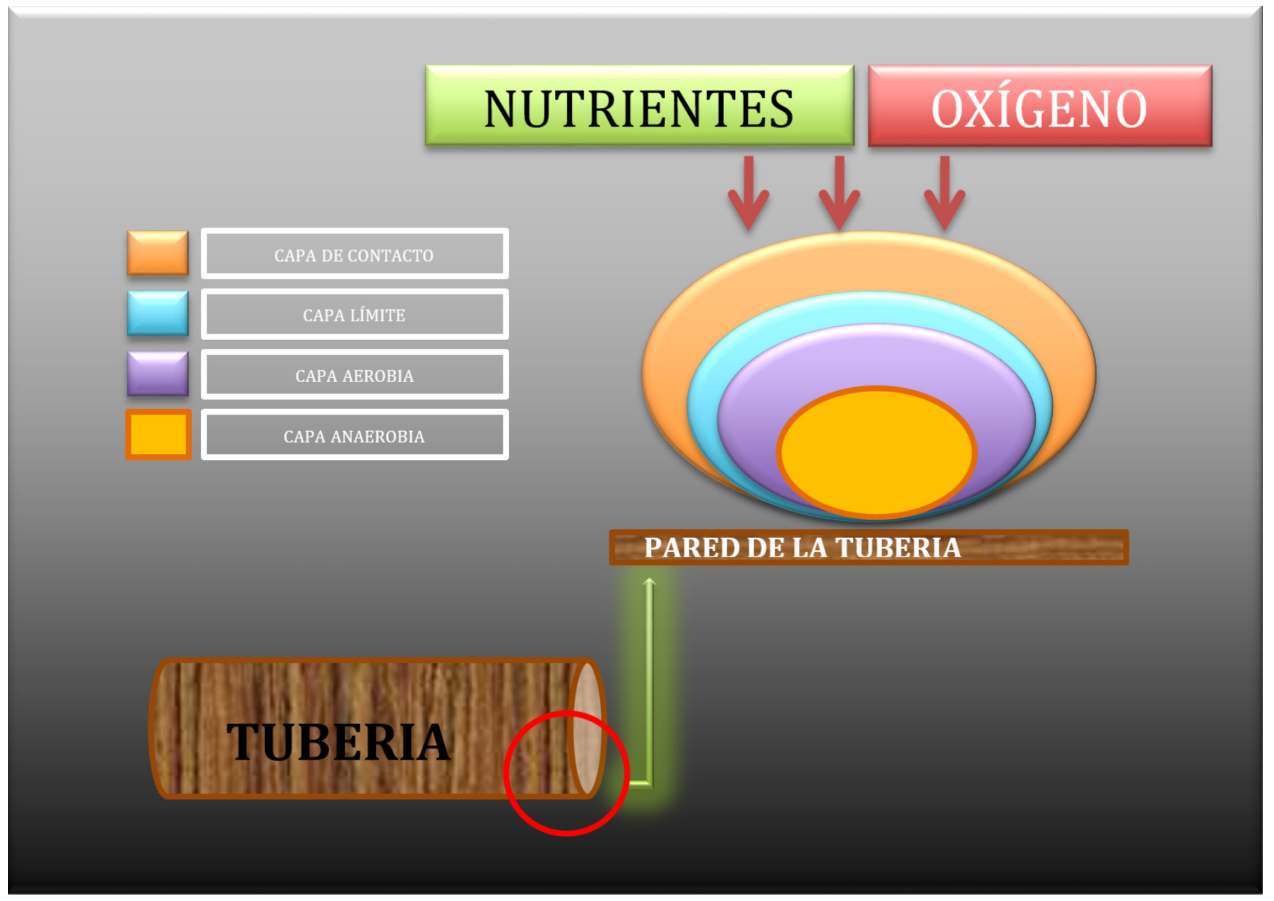

Fuente. Elaboración propia.

Más adelante, las células del biofilm podrán aislarse o desprenderse para volver a su vida planctónica. Cuando hacen el aislamiento, se cree que es generado por cierta maduración de las bacterias y por la reducción de nutrientes lo cual permite que migren a otro lugar para colonizar. También puede suceder por el desprendimiento que se ocasiona por tres motivos, uno es el deslizamiento provocado por la remoción del mismo biofilm, igualmente por movimiento rápido y masivo o por la liberación y colisión de partículas, ayudando a la vez al mismo biofilm a alimentarse con los ácidos nucleicos que se adquieren (5).

La estructura en capas de biopelículas (difusión limitada) combinado con las condiciones de flujo de agua, hace que estas colonias microbianas sean intrínsecamente resistentes a muchos biocidas y esquemas de limpieza. Las biopelículas se convierten entonces en el reservorio principal de contaminación continua del sistema $(3,4)$.

A pesar que los materiales de algunas tuberías, como las de plástico, no son tóxicas, se vuelven parte de la alimentación de las bacterias, en el caso de los ductos de hierro colado y acero fomenta el crecimiento debido a que los desinfectantes no se adhieren y siguen de corrido sin afectarlas. Por consiguiente, las biopelículas actúan como una fuente para la contaminación continua del agua, que operan como una infección cruzada y además generan un impacto físico en las válvulas de control y en la función de los instrumentos $(6,7)$.

\section{Microorganismos participantes en la for- mación del biofilm}

Las bacterias, dependiendo de su estructura, son capaces de generar uniones resistentes y otras no tanto, y se hace alusión a las Gram positivas y Gram negativas $(4,8-15)$.

\section{- Bacterias Gram negativas}

Se habla de la E. Coli y la Pseudomonas spp. Estas necesitan de enzimas y proteínas capaces de generar seńales y anclajes entre célula y célula que sean aptos para formar las biopelículas. En estos géneros 
se encuentran las proteínas de dominio (GGDEF) consideradas como trasmisor y sistema de comunicación o autoinducción, conocido como Quorum sensing $(4,8-15)$.

Para poder formar biofilm, las Pseudomonas necesitan de varias proteínas o péptidos señal, capaces de generar conexión tanto internamente como externamente, para ello necesita de un sistema de autoinducción conocido como Quorum sensing. Este sistema, como se dijo anteriormente, ayuda al microorganismo a reconocer la cantidad de bacterias cercanas, entre más se intensifica este signo, más rápido se inicia la concentración de señales y por ende la activación de genes pronunciándose así los sistemas de comunicación célula a célula $(4,8-15)$.

La unión entonces comienza con la transcripción del gen lux, presente en las Pseudomonas y en la $E$. col conformado a su vez de luxl y $\operatorname{luxR}$, capaces de activar otros genes. Al terminar el primer paso para la expresión génica, se forman proteínas conocidas como LasR activada por luxR y LasI activada por luxI. Por otra parte, se codifica la enzima $A H L$ (acetil homoserina lactonasa) por medio del gen att $M$; esta se une a la proteína I (LasI), y juntas se ensamblan a la membrana interna de la bacteria, activando la bomba $M e x A B-O p r M(4,8-15)$.

MexAB-OprM es un canal que se divide en dos enzimas: $M \operatorname{ex} A B$ (atraviesa la membrana citoplasmática) y $O p r M$ (se encuentra en la membrana externa). $M e x A B$ junto a $O p r M$ se encargan de darle resistencia antimicrobiana ante algunos antibióticos que ingresan al microorganismo y son expulsados por esta bomba, para esto necesitan de una proteína lipídica (PS) ligada al exterior de ella (figura 2). Al formarse un complejo octaédrico de estas enzimas es probable el traspaso del plásmido, esto es más fácil de realizar si la bacteria se encuentra en fase exponencial, de lo contrario el gen attJ, es un stop mientras el microorganismo está en fase estacionaria y para entonces ya debe terminar la transferencia del plásmido (4, 8-15).
Figura 2. Composición de la bomba MexAB-OprM.

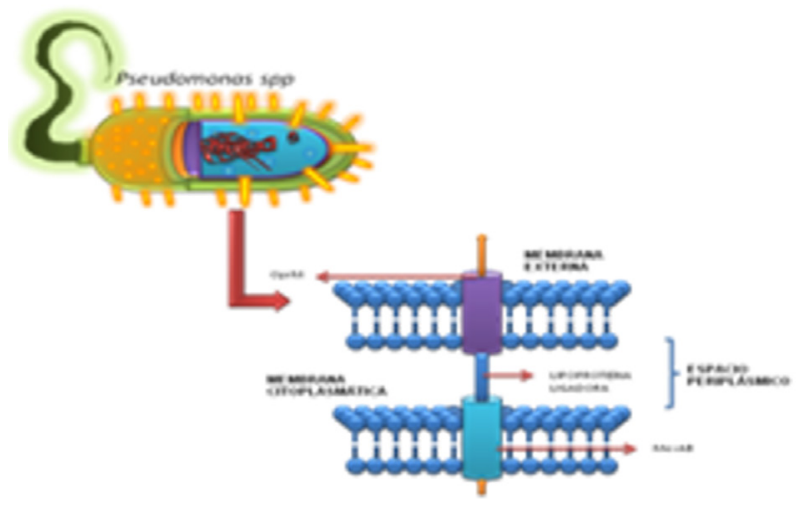

Fuente. Elaboración propia.

En la membrana también se une la proteína Lap $A$ (leucina aminopeptidasa), conformada por $L a p E$, Lap C, $\operatorname{Lap} B$, con ello, y el complejo ya mencionado, se genera la adhesión de célula a célula.

Mientras tanto, en la membrana, las proteínas I (LasI) y las proteínas $\mathrm{R}$ (LasR) empiezan el control de otros activadores transcripcionales $r h l$. Las $R$ regula la expresión de $r h l R$ y $L a s I$ la de $\operatorname{rbll}(4,8-15)$.

Otra molécula activadora de la formación de biofilm es el Diguanilato ciclasa que activa el mensajero secundario, el pili o fimbria también hacen parte de la asociación en la fase primaria y mientras se realiza el proceso de acoplamiento entre microorganismos las Pseudomonas producen un exopolisacárido de alginato que evitan que las fagociten o las eliminen, entre los exopolisacáridos existe un polisacárido enriquecido de glucosa llamado "Pellican", actuando de refuerzo (4, 8-15). Con la Escherichia coli es el mismo procedimiento, pero no se llama Las, sino CsrA.

\section{- Bacterias Gram positivas}

Los Staphylococcus epidermidis son considerados cocos Gram positivos, coagulasa negativa, es decir, no poseen fibrina o factor de aglutinación que cubre a la bacteria de opsonización y fagocitosis. Son anaerobios facultativos, catalasa positiva que se encarga de inactivar la toxicidad del peróxido de hidrogeno y radicales libres de los macrófagos y son flora normal de la boca (16-19). 
En las áreas dentales es frecuente encontrarlos en los equipos por la manipulación del personal (lavado de manos inadecuado). Estas bacterias se alimentan de la capa orgánica que se encuentra entre la interface y la superficie de la tubería, cambiando el estado de la superficie, con ello se mejora la fijación de los microorganismos (16-19).

En la formación de biofilm existen características que diferencian una bacteria Gram positiva de la Gram negativa, pero hay otras similares como lo es el dominio (GGDEF), en este caso necesitan de otro, el EAL. Las diferencias se notan al ver que en el caso de la Pseudomonas spp, poseen un flagelo; pero el Staphylococcus spp, al no ser móvil posee proteínas de superficie como AtlE, Bap, Esp, el exopolisacárido de galactosa-arabinosa y mientras que en las Gram negativas el autoinductor es la $A H L$, en estas son los péptidos señal (16-19).

Para el Staphylococcus epidermidis la formación de biopelícula inicia con la codificación del operón ica, éste parte del gen icaADB; con el complejo de genes se da lugar al antígeno capsular PS/A polisacárido capsular/adhesina, conformado por galactosa-arabinosa (16-19).

$P S / A$ permite, en primera instancia, la unión entre célula-superficie, icaA se encarga de codificar para PIA, un polisacárido de adhesión en tétradas trasmembranales, pero este gen necesita de la expresión de icaD para incrementar la expresión enzimática, con lo que icaA, icaD, icaB e $i c a C$ en la fase exponencial están en la producción de las proteínas de adhesión y con ello la acumulación de capas protectoras del biofilm. La expresión de PS/A, lleva a la unión célula-célula, junto al traspaso del plásmido que actualmente se conoce como $p c N 27$ (16-19).

El proceso termina cuando icaR (gen $i c a R$ ) entra a controlar la expresión de PIA, y a RIP como inhibidor de los péptidos señal, encargados de la autoinducción (16-19) (ver figura 3).

Figura 3. Esquema de la función del operón en la fase exponencial y estacionaria.

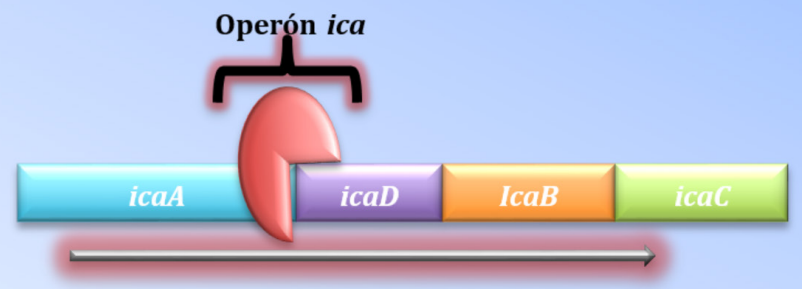

FASE EXPONENCIAL

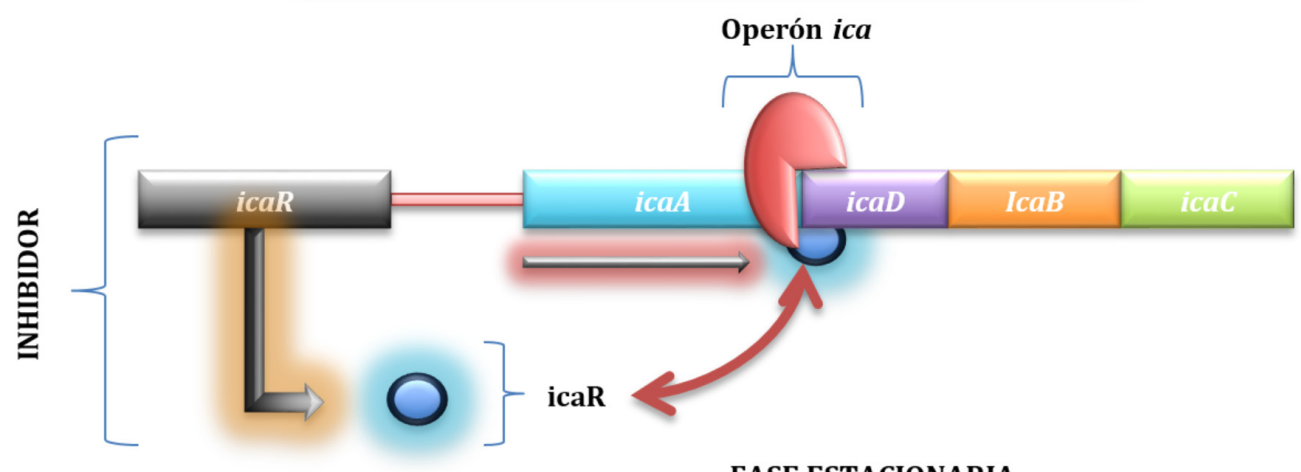

FASE ESTACIONARIA

Fuente. Elaboración propia. 


\section{Objetivo}

Recuperar y analizar la presencia de bacterias formadoras de biopelículas en las mangueras que distribuyen el agua a las unidades dentales de la Fundación Universitaria San Martin.

\section{Materiales y métodos}

En este trabajo se tomaron muestras de elementos de la clínica odontológica Prado Veraniego de la Fundación Universitaria San Martín, se ejecutó un estudio descriptivo de corte transversal con muestreo probabilístico.

La jeringa triple y la pieza de mano fueron seleccionadas al ser los instrumentos por los cuales transi- ta el agua que entrará en contacto con el paciente. En primer lugar, se tomaron 6 muestras antes y 6 muestras después de la consulta, de la jeringa triple con solo agua, con agua-aire y la pieza de mano; se recolectaron $150 \mathrm{~mL}$ de agua en frascos schott con tiosulfato de sodio al $10 \%$.

Las muestras se transportaron inmediatamente al laboratorio de la UCMC (Universidad Colegio Mayor de Cundinamarca) en una nevera de refrigeración y se procesaron por medio de la técnica de filtración por membrana. Se utilizaron membranas de nitrocelulosa con un poro de 0.45 micras, y se procedió a filtrar $50 \mathrm{~mL}$ de cada agua, para después colocarla sobre medios Endo, cetrimide y sangre azida. Se incubaron los medios de $35^{\circ}$ a $37^{\circ} \mathrm{C}$ de 24 a 48 horas con excepción del agar base sangre azida que se leyó hasta las 72 horas.

Imagen 1. Punto de conexión de las mangueras que enlazan la pieza de manos y la jeringa triple.

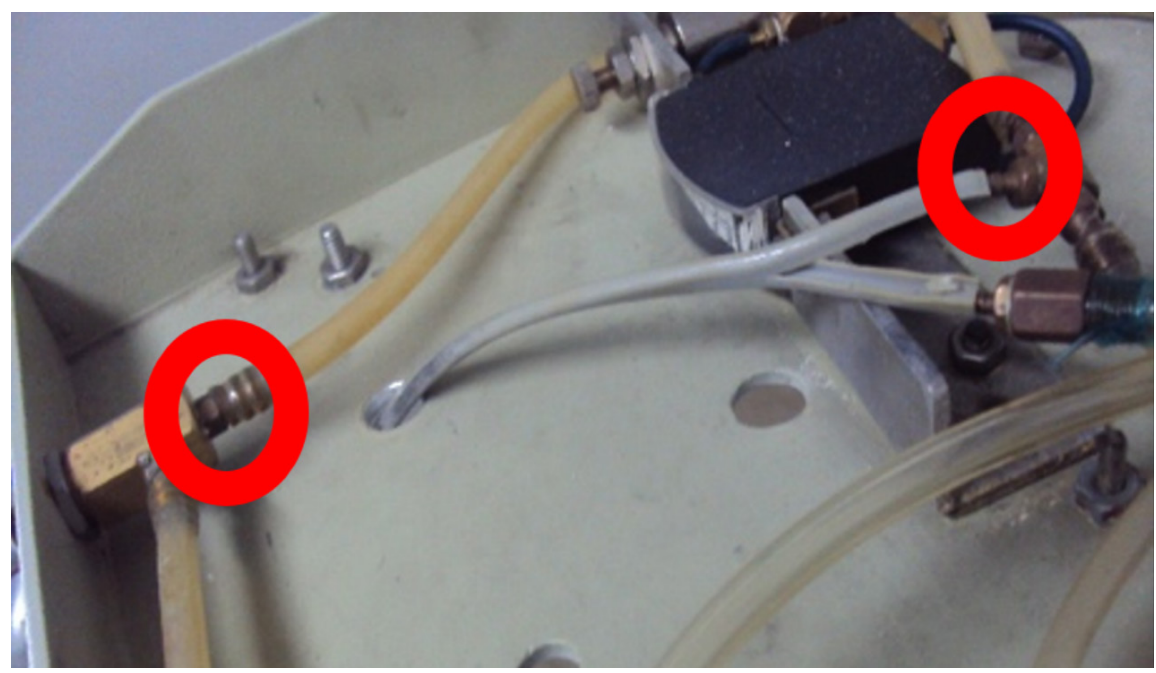

Fuente. Elaboración propia.

De otra parte, se tomaron doce muestras de las dos mangueras de los respectivos elementos escogiendo las unidades dentales al azar. Luego, se procedió a soltar las mangueras del punto de conexión conocido como bracket, el cual se bifurca hacia la derecha (pieza de mano) y hacia la izquierda (jeringa triple) (imagen 1); se desliza el escobillón en la boca del conducto y se introducen en tubos con BHI, con el fin de poder recuperar cualquier microorganis- mo presente. Las muestras fueron transportadas al laboratorio de la UCMC, en una nevera de refrigeración y se incubaron posteriormente a $37^{\circ} \mathrm{C}$ de 24 a 48 horas.

Pasadas las 48 horas se procede a realizar las siembras mediante estrías en Agar sangre y Agar Mac Conkey, y se incuba a $37^{\circ} \mathrm{C}$ de 18 a 24 horas. Culminadas las horas establecidas, se realiza repique a 
las colonias típicas en el Agar Sangre y MacConkey con el fin de obtener UFC puras.

A las 18 horas de incubación a $37^{\circ} \mathrm{C}$, se procede a realizar coloración de Gram y lectura de las colonias que han crecido. A continuación, se realiza la identificación de cada colonia bacteriana mediante el sistema BBL Crystal para Gram negativos y Gram positivos.

\section{Resultados y discusión}

Los resultados del crecimiento de bacterias indicadoras de contaminación en el agua, se muestran en las gráficas 1 y 2 . Los resultados obtenidos de las muestras en las mangueras de la pieza de manos y jeringa triple de las seis unidades dentales se presentan en la tabla 1 y gráfica 3.

Gráfica 1. Resultados obtenidos de UFC/50mL de E. coli en medio ENDO antes y después del tratamiento.

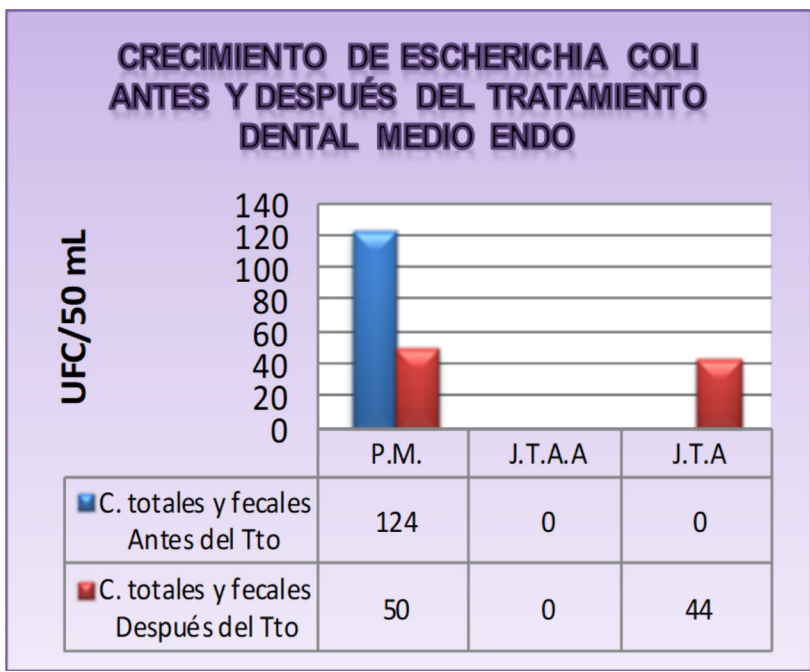

Fuente. Elaboración propia.
Gráfica 2. Resultados obtenidos de UFC/50mL de Pseudomonas sp. antes y después del tratamiento dental en medio cetrimide.

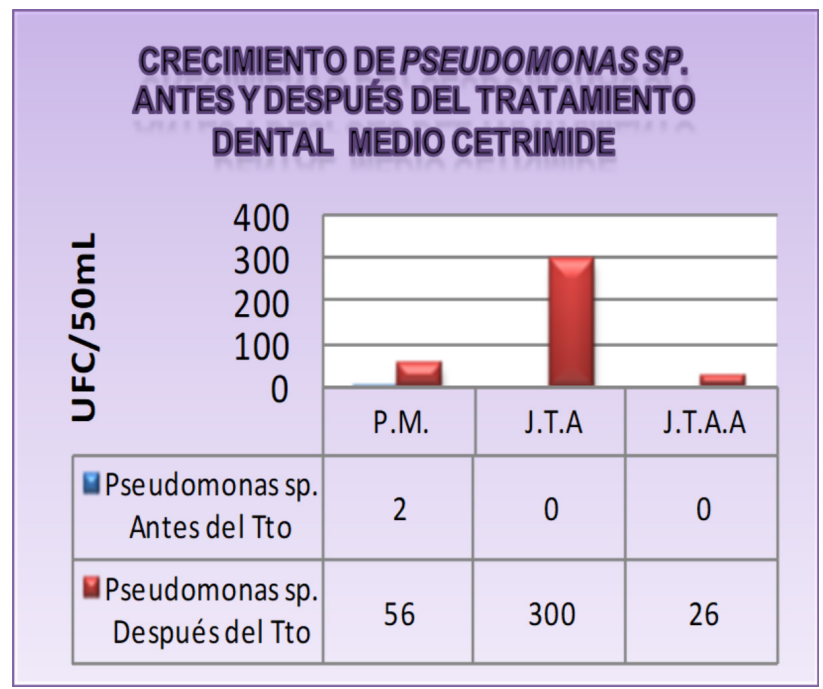

Fuente. Elaboración propia.

Gráfica 3. Resultados obtenidos de técnica de BBL Crystal. Comparación entre la presencia de Gram positivos y Gram negativos en el biofilm.

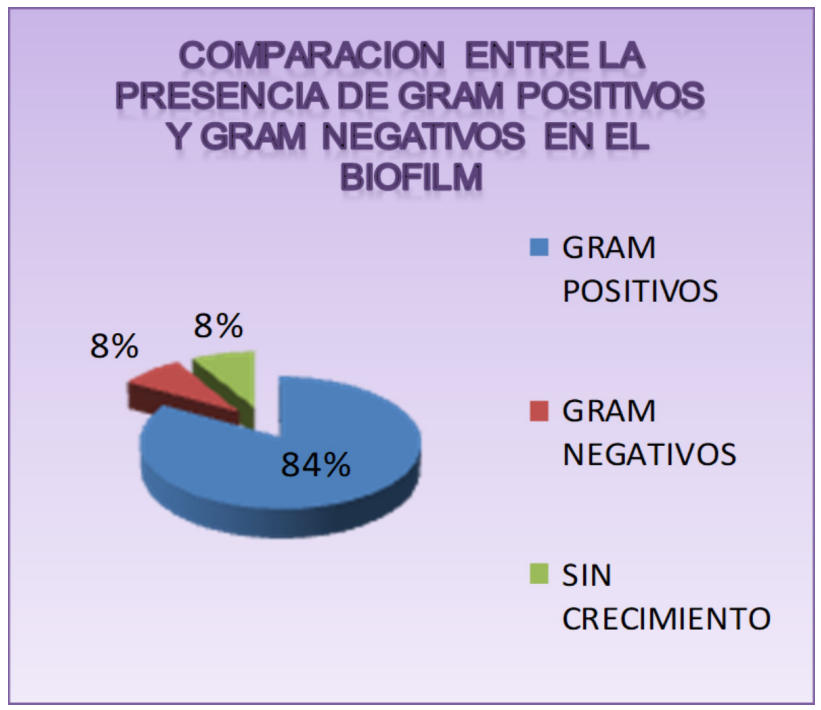

Fuente. Elaboración propia.

Según Arraigada y otros (20), la presencia de contaminación microbiana en el agua de las unidades dentales fue por primera vez reportada por Sciaky y Sulitzeanu en 1942, de ahí se empieza hablar de la implementación de una buena calidad bacteriológica del agua, cumpliendo así con los parámetros de aceptabilidad del agua potable para consumo humano. Igualmente, se reportan nuevas formas de 
contaminación en el área odontológica, se habla de microorganismos como bacterias aerobias, anaerobias, hongos, virus, protozoos; todos estos microorganismos formadores de biopelículas.

Tabla 1. Microorganismos identificados mediante la técnica BBL Crystal.

\begin{tabular}{|c|c|c|}
\hline Muestra & \multicolumn{2}{|c|}{ Microorganismo } \\
\hline \multirow{2}{*}{ Unidad dental 1} & $\begin{array}{l}\text { Manguera pieza } \\
\text { de manos }\end{array}$ & $\begin{array}{l}\text { Staphylococcus } \\
\text { hominis }\end{array}$ \\
\hline & $\begin{array}{l}\text { Manguera jeringa } \\
\text { triple }\end{array}$ & $\begin{array}{l}\text { Staphylococcus } \\
\text { epidermidis }\end{array}$ \\
\hline \multirow{2}{*}{ Unidad dental 2} & $\begin{array}{l}\text { Manguera Pieza } \\
\text { de manos }\end{array}$ & $\begin{array}{l}\text { Staphylococcus } \\
\text { epidermidis }\end{array}$ \\
\hline & $\begin{array}{l}\text { Manguera jeringa } \\
\text { triple }\end{array}$ & Sin crecimiento \\
\hline \multirow{2}{*}{ Unidad dental 3} & $\begin{array}{l}\text { Manguera pieza } \\
\text { de manos }\end{array}$ & $\begin{array}{l}\text { Staphylococcus } \\
\text { epidermidis }\end{array}$ \\
\hline & $\begin{array}{l}\text { Manguera jeringa } \\
\text { triple }\end{array}$ & Escherichia coli \\
\hline \multirow{2}{*}{ Unidad dental 4} & $\begin{array}{l}\text { Manguera pieza } \\
\text { de manos }\end{array}$ & $\begin{array}{l}\text { Staphylococcus } \\
\text { epidermidis }\end{array}$ \\
\hline & $\begin{array}{l}\text { Manguera jeringa } \\
\text { triple }\end{array}$ & $\begin{array}{l}\text { Staphylococcus } \\
\text { epidermidis }\end{array}$ \\
\hline \multirow{2}{*}{ Unidad dental 5} & $\begin{array}{l}\text { Manguera pieza } \\
\text { de manos }\end{array}$ & $\begin{array}{l}\text { Staphylococcus } \\
\text { epidermidis }\end{array}$ \\
\hline & $\begin{array}{l}\text { Manguera jeringa } \\
\text { triple }\end{array}$ & $\begin{array}{l}\text { Staphylococcus } \\
\text { epidermidis }\end{array}$ \\
\hline \multirow{2}{*}{ Unidad dental 6} & $\begin{array}{l}\text { Manguera pieza } \\
\text { de manos }\end{array}$ & $\begin{array}{l}\text { Staphylococcus } \\
\text { epidermidis }\end{array}$ \\
\hline & $\begin{array}{l}\text { Manguera jeringa } \\
\text { triple }\end{array}$ & $\begin{array}{l}\text { Staphylococcus } \\
\text { epidermidis }\end{array}$ \\
\hline
\end{tabular}

Fuente. Elaboración propia.

En este estudio, los resultados obtenidos demostraron el crecimiento de Escherichia coli en las mangueras de la pieza de manos y la jeringa triple, además de su presencia en el agua que es transita por estas dos piezas dentales.

Estas falencias pueden contribuir al inicio de enfermedades endodónticas en los pacientes.

El crecimiento de E. coli en la manguera y en el agua de la jeringa triple, después de la consulta dental, se debe al expulsar por segunda vez la salida del agua, lo que ocasionó el desprendimiento de bacterias agregadas anteriormente. Es decir, las biopelículas por parte de Escherichia coli. La presencia de este bacilo Gram negativo proporciona una fuente significativa de endotoxinas bacterianas, "lipopolisacáridos" (LPS) liberados de las paredes celulares de esta bacteria. Coleman y otros en Irlanda (6), indican que, al ser inhaladas, éstas pueden precipitar síntomas en las vías respiratorias. Además de que las concentraciones de las endotoxinas están directamente correlacionadas con la gravedad del asma. Resultados similares a esta investigación se encuentran en la investigación de Muñoz y otros en México (21), quienes evidenciaron en las mangueras e instrumentos de las unidades dentales crecimiento de Staphylococcus epidermidis y Escherichia coli.

La presencia de Pseudomonas ssp en la pieza de manos y en la jeringa triple puede tener varias probabilidades: la primera es debido a la contaminación por el medio ambiente, desde las redes de distribución que provee el agua potable hasta los tanques que almacenan y distribuyen el agua a todas las unidades dentales. La segunda, es debido al flujo lento de agua que genera "un estancamiento del agua" en las mangueras, propiciando la proliferación de este microorganismo; observándose más número de unidades formadoras de colonias en estos instrumentos dentales. La tercera es debido al deficiente mantenimiento periódico que debe realizarse en cuanto a la limpieza y desinfección del mismo como lo muestran Chacón y otros (22), quienes afirman que la factibilidad de recuperar este microorganismo se debe a que ella puede tener mecanismos de transmisión hídrica y tolerancia a condiciones nutricionales limitadas. Resultados similares se demostraron por Chacón (22), quienes demostraron la presencia de $P$. aeruginosa y $P$. fluorescens en el agua proveniente de la jeringa triple y el suministro externo.

Al no evidenciarse crecimiento de Pseudomonas aeruginosa en las mangueras de estos instrumentos dentales, no significa que no esté presente o que no forme biofilm. Puede deberse al insuficiente es- 
quema intensificado de recuperación para este microorganismo en la presente investigación.

El crecimiento de Staphylococcus epidermidis en la manguera de la pieza de manos y de la jeringa triple, coincide con los resultados de Lancelloti y otros en Brasil (23-26), donde argumentan la formación de biopelículas por parte del género Staphylococcus aureus y Staphylococcus epidermidis en líneas de agua.

Como el reflujo constante del agua desde la boca del paciente hacia las mangueras y tuberías conlleva a la fijación de estos microorganismos en la jeringa triple y en la pieza de mano, contamina la superficie de estos instrumentos dentales; lo que posiblemente genera un riesgo de contaminación cruzada entre pacientes y el personal (27-28).

Estas bacterias pueden llegar a ser patógenos oportunistas en el momento de presentarse un desequilibrio sistémico en el paciente. Por lo tanto, hay probabilidad del aumento de bacterias patógenas sobre las superficies y sobre la biopelícula dental en individuos inmunosuprimidos. Coleman y otros en Irlanda (6) indicaron que este microorganismo pertenece a la flora normal en la piel del ser humano y por ser manipuladas contaminan fácilmente; propiciando la proliferación de este microorganismo en las mangueras y por ende en las piezas que se utilizan en la boca del paciente.

\section{Conclusiones}

La presencia de microorganismos formadores de biopelículas son potencialmente una fuente significativa de contaminación cruzada y de infección cruzada en el entorno de la clínica dental.

Es necesario desinfectar adecuadamente tanto la instrumentación dental, como el área de trabajo y debe efectuarse en el momento de culminar el tratamiento dental en cada paciente, garantizándole una total inocuidad.
La implementación del control de calidad del agua en las clínicas odontológicas, es esencial; ya que, conociendo la situación bacteriológica de esta, se pueden establecer medidas correctivas como: programas de monitoreo periódico y la aplicación de medidas higiénicas preventivas en el manejo de los elementos utilizados en los tratamientos dentales.

\section{Referencias}

1. Castillo C. Presencia de Biofilm en el sistema de transporte de agua interno de las unidades dentales. [Trabajo de grado]. Guatemala; 2003..

2. Bartram J, and others. Heterotrophic plate counts and drinking-water safety: the significance of HPCs for water quality and human health. Revista World Health Organization. 2003.

3. Li J, Helmerhorst E, Leone C, Troxler R, Yaskell T, Haffajee A, Socransky S, Oppenheim P. Identification of early microbial colonizers in human dental biofilm. Revista Journal of Applied Microbiology. 2004; 97: 1311-1318.

4. Lasa I, Pozo L, Penadés R, Leiva J. Biofilms bacterianos e infección. Universidad pública de Navarra.

5. Jose C, Orgaz B. Las biopelículas microbianas, un búnker de uso habitual. Madrid; 2009. 129-145 p.

6. Coleman D, O’Donnell M, Boyle M, Russell R. Microbial biofilm control with in the dental clinic: reducing multiple risks. Journal of Infection Prevention. 2010; 11: 192-198.

7. Tyagi S, Kulkarni P, Prasad K. Science Regarding Dental Unit Waterlines (Duwl): A Review. Añas and Essences of Dentistry. 2010; 2: 108-113.

8. Nazar J. Biofilms bacterianos. Revista otorrinolaringología. 2007; 67: 61-72.

9. Uzcudun I. Biofilms Bacterianos. Universidad Pública de Navarra.

10. Hinsa S, Espinosa U, Ramos J and others. Transition from reversible to irreversible attachment during biofilm formation by Pseudomonas fluorescens WCS365 requires an ABC transporter and a large secreted protein. Revista pubimed. 2003; 49: 905-18.

11. Kjelleberg S, Givskov M. The Biofilm Mode of Life: Mechanisms and Adaptations. British Library Cataloguing Horizon bioscience; 2007.

12. Koval C, Gayman T, Kinsey A, Walsh A. Quorum Sensing in Pseudomonas aeruginosa; 2008.

13. Carmen Pedroza. Caracterización de la enzima acil homoserina lactonasa de una cepa de Bacillus thuringiensis. [Trabajo de grado]. Medellín; 2010.

14. Gómez C, Leal A, Pérez M, Navarrete M. Mecanismos de resistencia en Pseudomonas aeruginosa: Entendiendo a un 
peligroso enemigo. 2005; 53.

15. Yáñez M, Barberá V, Catalán V. Control de la contaminación microbiológica en unidades dentales. Gaceta Dental. 2005; 160: 54-60.

16. Moreno.M, Ruiz.E. Staphylococcus epidermidis formador de biofilm en blefaro conjuntivitis. Revista médica del Hospital General de México. 2007; 70 (1): 24 - 29.

17. Heilmann. C, Schweitzer. O, Gerke. C, Vanittanakom. N, Mack. D, Götz. F. Molecular basis of intercellular adhesion in the biofilm-forming Staphylococcus epidermidis; 2007.

18. Rivera. J, Zabala I. Caracterización fenotípica y genotípica de cepas de Staphylococcus sp. productoras de biofilm aisladas de quesos. [Trabajo de grado]. Maracaibo: Universidad del Zulia. Facultad Experimental de Ciencias; 2009.

19. Seija.V. Etiopatogenia microbiológica. Bacteriología y virología médica. 2009.

20. Arraigada A, Larrucea C, Padilla C. Control de Infección en los Ductos de Equipos Dentales de las Clínicas Odontológicas de la Universidad de Talca. Revista Dental de Chile. 2004; 95(2): 3-9.

21. Muñoz J, Hernández D, Moreno A. Calidad bacteriológica del agua de una clínica odontológica rural de la facultad de odontología de la universidad Autónoma de Zacatecas. Revista de la Asociación Dental Mexicana. 2002; 2: 52-59.

22. Chacón Ch, Isvelia M, Yepez G y otros. Aislamiento de especies de Pseudomonas de las líneas de agua de las unidades odontológicas. Acta odontológica venezolana. 2010; 48:1-8.

23. Lancellotti M, Pereira M, De Ávila F. Research on staphylococcus spp in biofilm formation in water pipes and sensibility to antibiotics. Brazilian Journal of Oral Sciences. 2007; 6(20): $1283-1288$.

24. Pinilla B Gladys, Chavarro P Bibiana, Moreno A Natalia, Navarrete O Jeannette, Muñoz M Liliana. Determinación de los genes, 16S ADNr, polA, y TpN47, en la detección de Treponema pallidum subsp. pallidum para el diagnóstico de sífilis congénita. Nova. 2015; 13 ( 24 ): 17-25.

25. Corrales Lucia Constanza, Antolinez Romero Diana Marcela, Bohórquez Macías Johanna Azucena, Corredor Vargas Aura Marcela. Bacterias anaerobias: procesos que realizan y contribuyen a la sostenibilidad de la vida en el planeta. Nova. 2015; $13(24)$ ) 55-81.

26. Carrero Sandra Helena Suescún, HerediaMontoya Dina Paola, Bolaños Yoryany Mulato, Medellín Martín Orlando Pulido. Seroprevalencia de infección por Leptospira y factores de riesgo en estudiantes de una universidad de Colombia. Nova. 2017; $15(27$ ): 131-138.

27. Zuluaga Martha, Robledo Sebastian, Osorio-Zuluaga German A, Yathe Laura, Gonzalez Diana, Taborda Gonzalo. Metabolomics and pesticides: systematic literature review using graph theory for analysis of references. Nova. 2016; 14 ( 25 ): 121-138.

28. Ávila de Navia Sara Lilia, Estupiñán-Torres Sandra Mónica, Díaz González Liliana. Calidad bacteriológica del agua
Vereda El Charco, San Miguel de Sema, Boyacá- Colombia. Nova. 2016; $14(25)$ : 139-145. 